\title{
ИСТОРИЧЕСКИЙ ОБЗОР НЕЙРОФИЗИОЛОГИЧЕСКИХ МЕХАНИЗМОВ ПСИХИЧЕСКИХ ЯВЛЕНИЙ
}

\author{
Папоян В. Р. (ЕГУ, Ереван, РА) \\ vpapoyan@ysu.am
}

\begin{abstract}
В статье представлены и проанализированы взаимоотношения между нейрофизиологическими процессами и такими психическими функциями как: мотивация поведения, ассоциации, связанные с познавательными процессами, проблемы нейрофизиологических механизмов различного происхождения переключения, которые лежат в основе ряда психических процессов. Основные принципы психологии, являющиеся методологическим фундаментом психологии и базирующиеся на достижениях естественных наук, обеспечивают познание механизмов, лежащих в основе проявлений психического. Актуальным и значимым является анализ экспериментальных и теоретических трудов Э. А. Асратяна, которые способствовали раскрытию нейрофизиологических и общих биологических основ отдельных психических процессов и явлений. Они направлены на определение и понимание более углубленных нейрофизиологических процессов, которые обеспечивают раскрытие их взаимоотношения с психическими функциями.
\end{abstract}

Ключевые слова: нейрофизиология, психические явления, переключение, мотивация, поведение, рефлекс.

Проблема, связанная с положением психологии в системе научных дисциплин, вопрос о месте психологии среди социальных и биологических наук - на сегодняшний день остается одним из самых спорных. Учитывая связь психики, психических процессов как основного предмета изучения психологии с биологией, сторонники естественнонаучного направления считают, что психология должна быть включена в число естественных наук т.к. психические процессы тесно связаны с генетически обусловленными морфофризиологическими признаками.

Основные принципы психологии, являющиеся методологическим фрундаментом психологии и базирующиеся на достижениях естественных наук, обеспечивают познание механизмов, лежащих в основе любых проявлений психического.

Психическая деятельность осуществляется посредством множества специальных фризиологических механизмов: одни обеспечивают восприятие воздействия, другие способствуют формированию сигналов в организме, планированию и регулированию поведения. Вся эта сложная система 
обеспечивает ориентацию и адаптацию организма в среде. Следовательно, психология представляет собой совершенно новую ступень качественного познания человека, различных сторон его проявлений, и опирается на конкретные разработки в области философии, социологии, культурологии, естественных наук и т.д. В связи с этим, неоднократно рассматривались вопросы относительно способа, на который должна опираться психология при образовании научных понятий: «либо на тот, что принят в науках о природе, либо на тот, что относится к культуре» [15].

Трудно согласиться с тем, что существуют такие виды сознательной деятельности человека, которые можно рассматривать как чисто биологические процессы, не подвергающиеся влияниям общественных форм жизни. Недостаточно также считать, что имеются какие-то виды сознательной деятельности, не зависящие от ряда биологических законов, значение которых полностью сохраняется и у человека.

Наши знания о мозге, о его функциях на уровне нейрона и связях с психикой к концу 20-го века обогатились и существенно изменились. Известно, что идеи И. П. Павлова были весьма весомыми и общепринятыми. Затем они были дополнены учениями Н. А. Бернштейна, П. К. Анохина, Е. Н. Соколовой, их учениками и последователями.

Группа ученых, разделив биологическое и социальное в психических процессах, изучив их отдельно друг от друга, пришла к заключению том, что удельный вес биологического и социального может различаться в разных сфрерах психической деятельности, что в одних психических процессах человека преобладает биологическое, в других - социальное начало.

Этот подход получил в истории психологии название теории двух факторов, и именно из этой теории исходили многочисленные попытки американских психологов изучить соотношение биологического и социального, измерить удельный вес обоих факторов в различных формах психической жизни человека и трактовать психическое развитие как процесс постепенного увеличения роли социального фактора (вводимого с помощью обучения) и уменьшения значения биологического фактора. Считалось, что именно этим количественным изменением соотношения обоих факторов и характеризуется психическое развитие [14].

Учеными отмечено, что психические явления непосредственно связаны с работой головного мозга. Из истории психологии известно, что из двух областей науки, как физиологии и психологии сформировались две специальные науки - физиология высшей нервной деятельности и психофизиология. Для этих двух направлений общим стало понятие научение. Ими были исследовано и проанализировано понятие научение, включающее в себе явления, связанные 
с памятью, переходящей в приобретенный опыт на анатомо- физиологическом, психологическом и поведенческом уровнях.

Психические состояния имеют рефрлекторную природу. Они возникают под влиянием обстановки, фризиологических факторов, хода работы, времени и т.д.. Психическое подчиняется специфическим закономерностям, раскрываемым психологией, и в тоже время на него целиком и полностью распространяются все фризиологические, фризико-химические и др. закономерности. На основе такого подхода объективно определяются гуманистический статус психологии человека (по отношению к физиологии) и ее участие в построении обшей картины мира.

Психологическая наука едина, поскольку в психике человека природное и социальное всегда неразрывны, взаимосвязаны, начиная с пренатального возраста, что составляет исходную теоретическую основу для постановки и решения психофизиологической проблемы. Психические свойства являются и результатом нейрофизиологической деятельности мозга, содержат в себе характеристики внешних объектов, а не внутренних фризиологических процессов. На наш взгляд, психические явления соотносятся не с отдельными нейрофизиологическими процессами, а с организованными совокупностями таких процессов. Мозговые механизмы психических процессов человека имеют много общего с механизмами психики животного. Высшие интегративные системы мозга обладают рядом специфических механизмов, позволяющих им осуществлять взаимодействие практически всех сенсорных и моторных аппаратов. Более ярким проявлением мозга в «программировании» своей деятельности могут считаться выявленные в лаборатории И.П.Павлова и его учеников принципы переключения условных рефлексов, которые известны как динамический стереотип, представляющий собой целостные поведенческие акты.

Глобальным вопросом, адресованным всем естественно-научным дисциплинам психологии, является вопрос о наследственности и потенциальных ресурсах человеческого мозга в связи с информационными перегрузками. Поэтому большой интерес вызывает особый вектор развития современной нейропсихологии, связанный с объединением нейропсихологии и психофизиологии, в контексте проблемы «психофизиологические механизмы психических процессов и состояний».

Большой вклад в понимании того, как связана работа мозга и организма человека с психологическими явлениями и поведением, внес И.М. Сеченов. Позднее его идеи развил в своей теории И.П.Павлов, открывший явление условнорефлекторного научения, что послужило основанием для создания новых, более современных теорий, объясняющих научение и поведение в целом (Н. А. Бернштейн, К. Халл, П. К. Анохин), а также условнорефлекторного 
приобретения опыта (Е.Н.Соколов). Эволюция мозга привела к тому, что наша система организации в высочайшей степени саморегулирующаяся, самоподдерживающаяся, самовосстанавливающаяся, направляющая и даже совершенствующаяся. Аналогично тому, что условный рефлекс является центральным феноменом большого мозга, условнорефллекторная теория является сердцевиной учения высшей нервной деятельности. Исследования ученых позволили отметить, что с одной стороны психические процессы совместно с физиологическими управляют поведением, а с другой - в построении общих моделей регуляции поведения, участвуют физиологические и психологические явления (Н.А.Бернштейн, К.Халл, А.П.Анохин). По словам Н.А.Бернштейна, самое простое движение, приобретенное при жизни, сложная человеческая деятельность и поведение в целом, не могут быть выполнены без участия психики [9].

Физиологический механизм выработки условного рефлекса на электростимуляцию представляется в следующем виде: по существу, любой первичный рефлекс может рассматриваться как результат сочетания активности двух безусловных рефрлексов, как продукт их синтеза. Эта фрормула правильна как для случаев сочетаний, например, индиффферентного раздражителя с каким-нибудь биологически существенным раздражителем, так и для случаев сочетания двух типичных безусловных раздражителей: возможность вызвать разного рода поведенческие акты при электростимуляции одного и того же из этих образований.

Многими исследователями установлен фракт о том, что при электростимуляции одного и того же пункта и ядра гипоталамуса, или лимбической формации, можно вызвать самые разнообразные мотивационные поведенческие реакции фрункционального состояния организма; целенаправленный характер мотивационных поведенческих актов.

Э. А. Асратяном и его сотрудниками изучен процесс выработки отдельных условных рефлексов с двусторонними условными связями и их интеграции в сложные поведенческие реакции, а именно:

- процесс выработки условного рефлекса второго порядка на посторонний раздражитель;

- усложнение этой цепи путем выработки условного рефрлекса до действия какого-нибудь пускового раздражителя,

- синтез всех наличных условных рефрлексов в определенный динамический стереотип поведения, процесс переключения всей системы условных раздражителей от сигнализации одного рода деятельности к другой $[3,4]$.

По каждому из этих вопросов есть разногласия. Суть их может быть лучше понята, если в модели ВНД будет учтено также представление о нервном 
центре как совокупности нервных структур, расположенных в разных частях большого мозга.

Актуальным и значимым является анализ экспериментальных и теоретических трудов Э. А. Асратяна, которые способствовали раскрытию нейрофизиологических и общих биологических основ отдельных психических процессов и явлений. Они направлены на определение и понимание более углубленных нейрофизиологических процессов, которые обеспечивают раскрытие их взаимоотношения с психическими фрункциями. Прежде всего нужно отметить вопросы мотивации поведения, ассоциаций, связанных с познавательными процессами, проблемы нейрофизиологических механизмов различного происхождения переключений, которые лежат в основе ряда психических процессов. Современные нейрофизиологи, экспериментальные психологи, изучающие фрункции субкортикальных нервных образований, их связи и взаимодействия с корой, получили ценный по научному значению фактический материал, послуживший основанием для концепций и гипотез по мотивационному поведению, подтвердили рефлекторный характер сложнейших поведенческих реакций, известных в современной науке под названием мотивационных. Новое понимание механизмов психических явлений доказывает междисциплинарную связь между психологией и фризиологией. Физиологи научное решение многих вопросов находят на стыке фризиологии высшей нервной деятельности (ВНД) и психологии. Принципиальные вопросы по проблеме мотивации, в целом, могут быть осмыслены в свете основных теоретических положений И. П. Павлова о ВНД. Проблема мотивационного поведения, возникшая в недрах психологии и длительное время разрабатываемая психологами различных направлений, позволила Э. А. Асратяну обсудить три важных вопроса:

- участие множества церебральных нервных образований в осуществлении одних и тех же специфических мотивационных поведенческих актов;

- вариабельность этих актов в зависимости от эндогенных и экзогенных факторов и особенностей их структурно-функциональной организации;

- нейрофизиологические механизмы целенаправленного характера мотивационных двигательных актов [6, 7].

Одной из причин противопоставления «мотивационного» поведения другим фрормам поведения и провозглашения «мотивационного» поведения нерефлекторным по своей природе является тот фракт, что направляемое той или иной мотивацией поведение иницируется и развертывается не в ответ на определенный условный стимул, а «изнутри», и принципы рефлекторной теории неприменимы. Таким образом, огромный класс поведенческих реакций провозглашается «не- или надрефлекторным» и исключается из сореры детерминистского изучения и анализа. Заслугой Э. А. Асратяна является убеди- 
тельное научно-теоретическое опровержение такого подхода, доказательство его фрактической несостоятельности.

Существует точка зрения, согласно которой ведущим началом целенаправленных действий животного и его мотивационного поведения, в целом, являются разного рода влечения, недетерминириванные внешними факторами и выражающие потребности организма, обусловленные изменениями в гипоталамической области. И. С. Бериташвили ведущую роль в поведенческих реакциях приписывает образной психонервной деятельности. А.П.Анохин интерпретирует мотивационное поведение в свете своей концепции о так называемой функциональной системе. Есть основания предполагать, что именно современная динамическая, эволюционная по своей сущности рефрлекторная теория способна пролить наиболее яркий свет на сложную проблему современной нейрофизиологии и экспериментальной психологии[1]. Общепринято, что одной из наиболее характерных и существенных особенностей мотивационного поведения является выбор и осуществление целенаправленных действий животных в виде тех или иных комплексов специализированных двигательных актов, которые протекают по механизму оперантного поведения. Целенаправленный характер мотивационного поведения Толмен приписывает «карте познания», сорормированной в индивидуальной жизни особи [17], И. С. Бериташвили - направляющему влиянию психонервного образа. В основе понимания Э. А. Асратяном этого вопроса лежит идея И. П. Павлова о двусторонней условной связи, что занимает существенное место в механизме сложных поведенческих актов, именуемых мотивационными.

В научном творчестве Э.А.Асратяна оценивается его роль в стремлении к синтезу науки ВНД с общей нейрофизиологией, психофизиологией и психологией. Он объединил классическую физиологию с психологической наукой, которые до его исследований и научных обоснований представляли относительно сепаратные области исследований. Научно-теоретической базой физиологии и психологии является рефлекторная теория и учение о ВНД. Э.А.Асратяном выдвинут принцип взаимодействия прямых и обратных связей между рефрлексами, который позволил понять рефрлекторный механизм целенаправленного и активного поведения живого организма. В целом труды Э.А.Асратяна посвящены анализу роли коры больших полушарий в компенсации утраченных функций; явлению переключения в условнорефлекторной деятельности; уровням безусловного рефлекса и т.д.. Теоретические обобщения относительно вышеперечисленных исследований способствуют большему взаимопониманию между физиологами и психологами, что в свою очередь поможет наполнить более углубленным научным содержанием психологические понятия. Заимствуя у Павлова понятие и термин подкрепление 
и придавая огромное значение акту подкрепления в процессе обучения разного рода навыкам, Э. А. Асратян отметил, что безусловный раздражитель через вызываемый им безусловный рефлекс оказывает подкрепляющее действие.

Не менее важной проблемой в психофизиологии является принцип ассоциации. Представители гештальтпсихологии утверждали, что целостность поведенческих реакций создается у антропоидов по механизму и закономерностям выработки и интеграции условных рефлексов. Среди высказанных И. П. Павловым идей по разным вопросам поведения антропоидов, особое место занимает его идея о существовании новой фрормы временной связи. Он употреблял термин «временная связь» и «ассоциация»как синонимичные. Временная связь - это универсальное фризиологическое явление, а ассоциация - психологическое [5].

Если учесть то обстоятельство, что идея ассоциации возникла и развивалась в недрах психологии, в основном, как проявление материалистического миропонимания, как выражение детерминистического подхода к пониманию генеза и сущности психических явлений, то понятно положительное отношение к этой идее. Каждая маленькая, первая ассоциация это есть момент рождения мысли. Мышление становится глубже, когда ассоциации растут и увеличиваются. Мышление непременно начинается с ассоциаций, с синтеза, затем идет соединение работы синтеза с этим анализом.

В психологии вопрос ассоциации до сих пор не считается удовлетворительно решенным, хотя многими психологами делались неоднократные попытки дать классификацию разновидностей ассоциации по тому или иному принцип по смежности, сходству, контрасту и пр. Э. А. Асратян в труде «Очерки по ВНД" пишет, что характеристика И.Павловым условного рефлекса как центрального явления в ВНД, а ассоциации как основы психической деятельности - это формулировка единого и основного принципа его учения о деятельности мозга соответственно на «языке» психологии - при помощи психологических понятий и терминов [2].

Проблема детерминации процессов обучения и памяти - одно из главных направлений фризиологии нервной системы. В основе памяти лежат ассоциации или связи. С фризиологической точки зрения ассоциации представляют собой временную нервную связь. Нейрофизиологическое и психологическое наследие Э. Асратяна представляет большой научный интерес для раскрытия нейрофизиологических основ психической деятельности, что очень важно, на наш взгляд, для истории психологии. Благодаря его трудам мы имеем более углубленные представления о мозговых механизмах, взаимоотношениях между нейрофизиологическими процессами и психическими функциями.

Учение нейрофизиолога Э. А. Асратяна проникает в психологию, в частности, экспериментальную психологию, служит основанием для современных 
нейрофизиологов, изучающих функции мозга. Он отметил, что являясь учениками и последователями И.Павлова, творчески развивая его богатейшее научное наследие по намеченным им путям, ученые преследуют те же цели, что и он.

Благодаря трудам Э. Асратяна мы имеем представления о взаимоотношениях между нейрофизиологическими процессами и их психическими функциями: мотивации поведения, ассоциации, связанные с познавательными процессами, проблемы нейрофизиологических механизмов различного происхождения переключения, которые лежат в основе ряда психических процессов. Он распространил на условнорефлекторную деятельность универсальный нейрофизиологический принцип зависимости реакций от предварительно совершающейся преднастройки нервной системы в целом, переключения ее именно на эту реакцию.

И. Ленгафт в «Вопросах психологии» отметил, что Э. А. Асратян вместе с К. М. Быковым рассмотрели вопрос о возникновении и характере условного рефлекса. Д. И. Дубровский в работе «Психические явления и мозг» остановился на том фракте, что Э. А. Асратян отождествляет психическую деятельность с ВНД. По убеждению Э. А. Асратяна, учение И. П. Павлова - это «гранитный естественнонаучный фундамент теории отражения». С точки зрения рефлекторной теории любой поведенческий акт, любая фрункция головного мозга носят рефлекторный характер. Вместе с П. В. Симоновым он утверждает, что любая наисложнейшая деятельность мозга - суть рефлекса. Явление динамического стереотипа, переключения, ситуационный условный рефлекс как один из вариантов комплексного условного рефлекса и т.д. представляют собой сложные интегральные образования. Однако это не значит, что интегральность условного рефлекса равнозначна интегральной целостной деятельности мозга, что для объяснения всех фрорм целостной деятельности мозга рефлекторная теория достаточна.А.В.Запорожец в своей работе «Развитие произвольных движений» отметил, что своеобразные двигательные условные рефлексы составляют фризиологическую основу произвольных движений. Другие пытались применить основные принципы павловской теории произвольных движений к фризиологии человеческих навыков, определив их как сложные проприоцептивные условные рефлексы, а затем как двигательные динамические стереотипы [11]. В дальнейшем Э. А. Асратян и др. развивали важное для психологии произвольных движений положение сеченово-павловской теории о ведущей роли сенсорной, аффрерентной части в структуре рефрлекторных актов, рефлекторных двигательных систем.

В труде Б. М. Теплова «Некоторые вопросы изучения общих типов ВНД человека и животных» отмечено, что И. П. Павловым раскрыто третье свойство 
нервной системы, (наряду с силой и уравновешенностью) - подвижность нервных процессов, и, как следствие этого, им создан окончательный вариант классификации индивидуальных типов по трем свойствам [16]. Тем не менее некоторый материал для изучения индивидуальных типов дан Э. А. Асратяном в статье о фризиологической лабильности [12].

В литературе учеными высказывались мысли о некоторых «новых» свойствах, не предусмотренных в павловской системе. Об этом свидетельствует Э. А. Асратяном впервые выдвинутая идея о «прочности» как особом свойстве, заслуживающая большого внимания, в особенности, по отношению к типологическим различиям ВНД человека.

М. Н. Ливановым, Т. М. Ефрремовым рассматривается положение о том, что все акты сознательной и бессознательной жизни по способу происхождения - это рефлексы, любая реакция организма это ответ на реально существующий стимул [13].

Открытие И. М. Сеченовым центрального торможения дало возможность подойти к решению целого ряда сложнейших проблем нейрофизиологии, в том числе регуляции и управления движениями и трактовки психических процессов на рефрлекторной основе. Большой вклад в ее изучение внесли Н. Введенский, А. Ухтомский, Э. Асратян, П. Анохин и др.

Исследование принципов детерминации обучения и памяти было и осталось одним из главных направлений ВНД. В разработке этих принципов велика роль Л. А. Орбели, Э. А. Асратяна, И. С. Бериташвили.

Современная рефлексология широко распространилась в направлении включения отдельных психологических и физиологических проблем, которыми занимались Лурия, Асратян, Бериташвили, исследования которых внесли новый вклад в нейрофизиологию и психологию, показали связь между поведением и функциями мозга. Развитие эволюционной физиологии раскрывает новые возможности для объяснения тончайших механизмов, обеспечивающих целостную условнорефлекторную деятельность индивида. Среди всех специфических особенностей условного рефлекса сигнальность претерпевает наиболее глубокие количественные и качественные изменения в процессе его эволюции и считается олицетворением принципа в рефлекторной деятельности нервной системы.

Необходимо полагать, что нейрофизиология, психофизиология и психология представляют органическое единство и действуют как единый понятийный аппарат, и для дальнейшего развития учения о ВНД необходим теснейший союз физиологии с психологией.

\section{Литература}


1. Анохин П.К. Биология и нейрофизиология условного рефрлекса, Изд-во медицина, М., 1968.,с.546

2. Асратян Э.А. Очерки по высшей нервной деятельности. Ереван: Изд-во АН Арм ССР.1977. 348с.

3. Асратян Э.А. Условные рефрлексы классические и инструментальные. Природа, 1967, вып.3, с.19-24

4. Асратян Э.А. Инструментальная разновидность условных рефлекснервнойов . В кн. Физиология высшей нервной деятельности. Под ред. В.Н.Черниговской. М., Наука., 1970., с.169-205

5. Асратян Э.А. Об одной глубокой идее И.П.Павлова. Журнал высшей нервной деятельности, 1970, т.20, вып.2, с.269-279

6. Асратян Э.А. Некоторые вопросы проблемы мотивации в свете учения И.П.Павлова. Журнал высшей нервной деятельности, 1976, т.26, вып.5, c.945-953

7. Асратян Э.А. Проблема мотивации в свете учения И.П.Павловая. XXI Международный конгресс. Париж.1976.М.

8. Асратян Э.А. О лабильности нервных процессов больших полушарий мозга. XV Международный физиолог.конгресс. Тезисы.М., Изд-во биол. и мед. лит., 1935,c.16-17

9. Бернштейн Н.А. Природа навыка и тренировка// Хрестоматия по общей психологии: Психология памяти.-М., 1979.- с.82).

10. Бехтерева Н.П. Здоровый и больной мозг человека/ Л.: Наука, 1988., 262c.

11. Запорожец А.В. Избранные психологические труды. Под ред. В.В.Давыдова, В.П.Зинченко,М.: Изд-во Педагогика.1986, том2,

12. Ильин Е.П. Психология индивидуальных различий. СПб.: Питер 2004.,701c.

13. Ливанов М.Н., Ефремова Т.М. Некоторые механизмы внутреннего торможения // Иван Михайлович Сеченов: к 150-летию со дня рождения. М., 1980. с. $194-209$

14. Папоян В.Р., Мурадян Е.Б. Естественно-научный аспект методологии психологии. Психология XXI столетия», Теория. Эксперимент. Социальная практика, 2009г.), Т.1. - Москва, Кострома: КГУ им. Н.А. Некрасова, Кострома 2009, с.271-275

15. Петровский А.В., Ярошевский М.Г. Теоретическая психология: Учеб. Пособие/ М.: Издат. Центр “Академия”, 2001., 496с.

16. Теплов Б.М. Избранные труды., М.:Педагогика 1985. 328с.

17. Толмен Э. Когнитивные карты у крыс и у человека. Хрестоматия по остории психологиия. Под ред.Гальперина П.Я., Ждан А.Н.М.: Изд-во МГУ,1980, с.63-69 


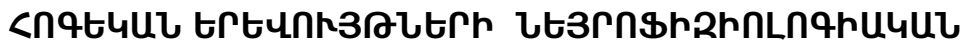

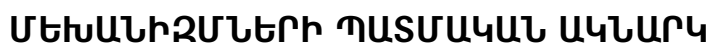

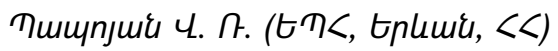

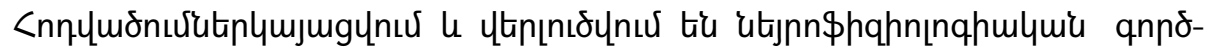

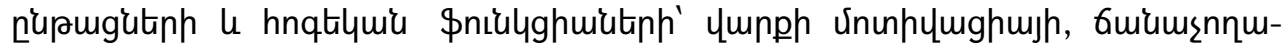

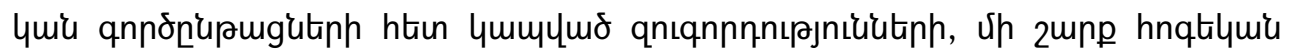

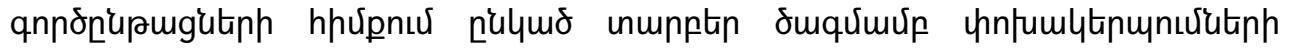

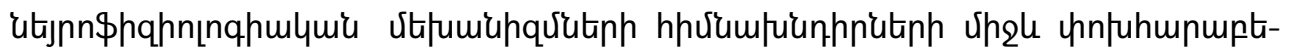

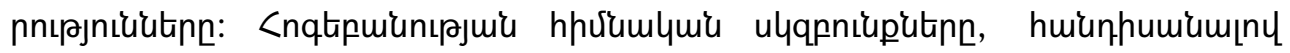

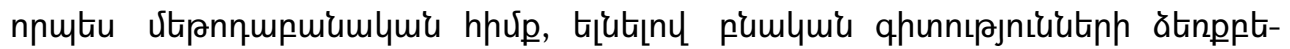

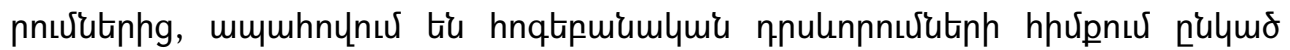

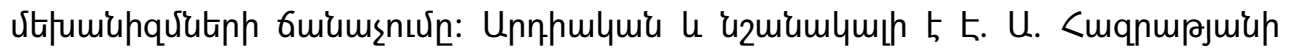

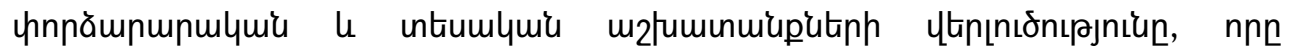

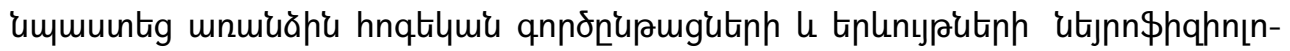

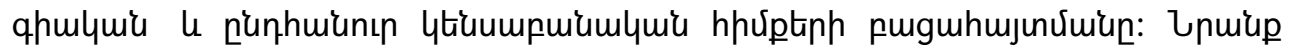

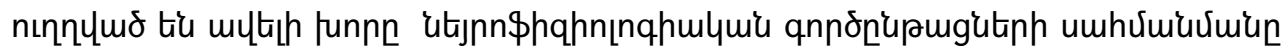

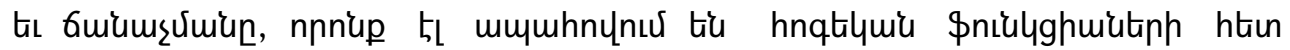

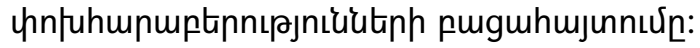

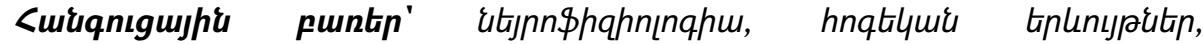

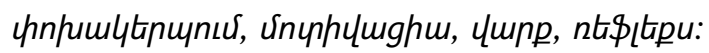

\section{HISTORICAL REVIEW OF NEUROPHYSIOLOGICAL MECHANISMS OF MENTAL PROCESSES}

Papoyan V. R. (YSU, Yerevan, RA)

The article is dedicated to finding out the connections between neurophysiological processes and such mental functions, as: motivation of behavior, associations, connected with cognitive processes, problems of neurophysiological mechanisms of different origins of switching, which are in the basis of some psychic processes. Main principles of psychology, which represent methodological fundament of psychology and are based on the achievements of natural sciences, provide the exploration of the mechanisms. Analysis of explorational and theoretical researches of E. Hasratyan, which provided the discovery of neurophysiological and general basics of some mental processes, remains significantly important. They are directed to defining and understanding deeper neurophysiological processes, which explain their connection to mental functions.

Key words: neurophysiology, mental processes, switching, motivation, behavior, reflex. 